\title{
Outcomes and effectiveness of posterior occipitocervical fusion for suboccipital spinal metastases
}

\author{
Panya Luksanapruksa, MD,1 Jacob M. Buchowski, MD, MS, ${ }^{2}$ Neill M. Wright, MD, ${ }^{3}$ \\ Frank H. Valone III, MD, ${ }^{2}$ Colleen Peters, MA, ${ }^{2}$ and David B. Bumpass, MD ${ }^{4}$
}

\begin{abstract}
1Department of Orthopaedic Surgery, Faculty of Medicine, Siriraj Hospital, Mahidol University, Bangkok, Thailand; Departments of ${ }^{2}$ Orthopaedic Surgery and ${ }^{3}$ Neurosurgery, Washington University in St. Louis, Missouri; and ${ }^{4}$ Department of Orthopaedic Surgery, University of Arkansas for Medical Sciences, Little Rock, Arkansas
\end{abstract}

\begin{abstract}
OBJECTIVE The incidence of suboccipital spinal metastases is rare but has increased given cancer patients' longer life expectancies. Operative treatment in this region is often challenging because of limited fixation points due to tumor lysis, as well as adjacent neural and vascular anatomy. Few studies have reported on this population of cancer patients. The purpose of this study was to evaluate clinical outcomes and complications of patients with suboccipital spinal metastases who had undergone posterior occipitocervical fixation.
\end{abstract}

METHODS A single-institution database was reviewed to identify patients with suboccipital metastases who had undergone posterior-only instrumented fusion between 1999 and 2014. Clinical presentation, perioperative complications, and postoperative results were analyzed. Pain was assessed using the visual analog scale. Survival analysis was performed using a Kaplan-Meier curve. The revised Tokuhashi and the Tomita scoring systems were used for prognosis prediction.

RESULTS Fifteen patients were identified, 10 men and 5 women with mean age of $64.8 \pm 11.8$ years (range 48-80 years). Severe neck pain without neurological deficit was the most common presentation. Primary tumors included lung, breast, bladder, myeloma, melanoma, and renal cell cancers. All tumors occurred in the axis vertebra. Preoperative Tokuhashi and Tomita scores ranged from 5 to 13 and 3 to 7, respectively. All patients had undergone occipitocervical fusion of a mean of 4.6 levels (range 2-7 levels). Median survival was 10.3 months. In all cases, neck pain markedly improved and patients were able to resume activities of daily living. The average postoperative pain score was significantly improved as compared with the average preoperative score $(1.90 \pm 2.56$ and $5.50 \pm 2.99$, respectively, $p=0.01)$. Three patients experienced postoperative medical complications including urinary tract infection, deep vein thrombosis, myocardial infarction, and cardiac arrhythmia. In the follow-up period, no wound infections or reoperations occurred and no patients experienced spinal cord deficits from tumor recurrence.

CONCLUSIONS Posterior-only occipitocervical stabilization was highly effective at relieving patients' neck pain. No instrumentation failures were noted, and no neurological complications or tumor progression causing spinal cord deficits was noted in the follow-up period.

https://thejns.org/doi/abs/10.3171/2016.10.SPINE16392

KEY WORDS suboccipital spinal metastases; occipitocervical fusion; cervical spine; posterior surgery; oncology

$\mathrm{T}$ HE incidence of symptomatic spinal metastases has increased given cancer patients' longer life expectancies. ${ }^{27}$ While metastatic lesions of the craniocervical junction $(\mathrm{CCJ})$ are relatively rare, they can pose serious problems because of the risk of craniocervical instability and catastrophic neurological compromise. Moreover, stabilizing the CCJ and upper cervical spine is often difficult because of the limited number of available fixation points for instrumented cervical fusion, particularly if substantial bone lysis has occurred from the tumor. Operative treatment should be considered in patients who present with instability, neurological compromise, or persistent pain after nonoperative therapy. ${ }^{17}$ Previous series have reported on the use of anterior-only, posterior-only, or combined surgical approaches for these tumors. ${ }^{1-3,6,8-10,13,16,18,19,21,24,26,28}$

The purpose of this study was to evaluate clinical out-

ABBREVIATIONS ASA = American Society of Anesthesiologists; $\mathrm{ASIA}=$ American Spinal Injury Association; $\mathrm{CCJ}=$ craniocervical junction; $\mathrm{RT}=$ revised Tokuhashi; $\mathrm{SIN}=$ Spinal Instability Neoplastic; VAS = visual analog scale.

SUBMITTED April 6, 2016. ACCEPTED October 20, 2016.

INCLUDE WHEN CITING Published online February 24, 2017; DOI: 10.3171/2016.10.SPINE16392. 
comes after posterior-only instrumented cervical fusion in patients with suboccipital metastases. To our knowledge, this is the largest posterior-only study published to date on suboccipital spinal metastases managed with occipitocervical fixation.

\section{Methods}

After institutional review board approval was obtained, we reviewed our institutional database for patients who had undergone surgery for suboccipital metastases between 1999 and 2014. Inclusion criteria were metastatic lesions involving the occipital condyles, C-1 vertebra, or C-2 vertebra that were treated with posterior-only instrumented cervical fusion. Patients were excluded if they had concurrent anterior cervical surgery or vertebroplasty. Charts and radiographic outcomes were reviewed (P.L. and F.H.V.).

Demographic data, presenting symptoms, comorbidities, previous treatments (radiotherapy, chemotherapy, and surgery), and radiographic studies were reviewed. Ambulatory status was classified as nonambulatory, ambulatory with pain, and ambulatory without pain. Pain was assessed using the visual analog scale (VAS). Neurological status was classified using the American Spinal Injury Association (ASIA) scoring preoperatively and at all postoperative follow-up time points. ${ }^{7}$ Predicted survival was calculated using the revised Tokuhashi (RT) score ${ }^{22}$ and the Tomita score. ${ }^{23}$ Spinal instability was assessed by using the Spinal Instability Neoplastic (SIN) score. ${ }^{5}$ Clinical data including presenting symptoms, presented history, and radiographic studies were reviewed for calculating the SIN score. Operative data included the American Society of Anesthesiologists (ASA) physical status classification, estimated blood loss, operative time, type of instrumentation, type of bone graft, levels fused, and intraoperative complications. Postoperative data included complications, hospital length of stay, discharge status, reoperation, and survival. Survival was analyzed using the Kaplan-Meier method. Patients who were alive at the latest follow-up were considered as censored cases. A p value $<0.05$ was considered statistically significant.

\section{Results}

Fifteen consecutive patients with suboccipital metastasis were identified. There were 10 males and 5 females. Mean age at presentation was $64.8 \pm 11.8$ years (range $48-$ 80 years). Two patients who had undergone vertebroplasty were excluded; no patients who had undergone combined anterior and posterior approaches were identified. Mean body mass index was $26.60 \pm 4.38 \mathrm{~kg} / \mathrm{m}^{2}$ (range 19-34.3 $\mathrm{kg} / \mathrm{m}^{2}$ ), and the mean Charlson Comorbidity Index was $9.73 \pm 1.57$ (range 7-12). Nine patients (60\%) were ASA Class 3.

Primary tumor pathology included lung (4 cases), breast (4), bladder (2), melanoma (2), multiple myeloma (2), and renal cell (1) tumors. All lesions were found in the C-2 vertebra. The mean preoperative RT score was $7.92 \pm 2.09$ (range 5-13). Six patients (40\%) had an RT score below 8 . However, all patients had Tomita scores below 8 (range $3-7$ ), correlating with predicted survival $>6$ months. The prognostic score could not be calculated in 1 patient because of insufficient data.

All patients presented with intractable neck pain that affected activities of daily living, but none had neurological deficits (15 patients with ASIA Grade E). Thirteen patients ambulated with pain, and 2 patients were nonambulatory secondary to neck pain. Ten patients $(66.7 \%)$ had multilevel vertebral metastases, and 12 patients $(80 \%)$ had other bone metastases. Twelve patients (80\%) had previously undergone chemotherapy, and 4 patients $(26.7 \%)$ had received preoperative radiotherapy to the cervical spine. Fourteen patients $(93.3 \%)$ had pathological fractures or instability as demonstrated on dynamic radiographs, and 2 patients (13.3\%) had large osteolytic lesions of the dens without fracture but with signs of impending clinical mechanical instability (pain while upright and with neck range of motion). Three patients (20\%) had SIN scores between 10 and 12 (potentially unstable), and 2 of these 3 had undergone preoperative adjuvant treatment. Twelve patients had SIN scores between 13 and 18 (unstable). Because all patients had SIN scores above 7 (range 10-15), the indications for surgery were impending or actual spinal instability.

A mean of 4.6 levels were fused in each patient (range 2-7 levels). Mean operative time was 215 minutes (range 120-324 minutes), and mean intraoperative blood loss was $259 \mathrm{ml}$ (range $50-1100 \mathrm{ml}$ ). Instrumentation included occipital plates for proximal fixation in all patients (Fig. 1). Ten patients (66.7\%) underwent $\mathrm{C}-2$ instrumentation as part of occipitocervical fixation: pars screws (6 patients [40\%]), translaminar screws (3 patients [20\%]), and pedicle screws (1 patient [6.7\%]). For fixations extending distal to C-2, lateral mass screws were used. Posterior fusion was performed in all patients by using local bone autograft, demineralized bone matrix, allograft, or iliac crest graft. Intraoperative neuromonitoring of somatosensory evoked potentials and transcranial motor evoked potentials was performed in all cases. Three patients underwent posterior decompression for spinal cord compression resulting from tumor. No patient underwent anterior tumor debulking. A summary of clinical results appears in Table 1 , and individual patient data are summarized in Table 2 . Postoperatively, a hard cervical orthosis was used in 14 $(82 \%)$ of 15 patients. Average hospital stay was $7.2 \pm 3.7$ days (range 3-16 days). The majority of patients $(9 / 15)$ were discharged to home, and the others were discharged to skilled nursing facilities.

All patients reported marked improvement in neck pain and were able to ambulate without pain in the postoperative period. The average postoperative pain score improved significantly as compared with the average preoperative score $(1.90 \pm 2.56$ and $5.50 \pm 2.99$, respectively, $\mathrm{p}=0.01)$. No intraoperative complications were identified. Neither were there any postoperative neurological deficits or surgical site infections. Five postoperative medical complications occurred in 4 patients: urinary tract infection (1 case), supraventricular tachycardia (1), atrial fibrillation (1), deep vein thrombosis (1), and myocardial infarction (1). One patient suffered a myocardial infarction on postoperative Day 2 and died the same day. Postoperative adjuvant therapy included radiotherapy in 6 patients (40\%) and chemo- 


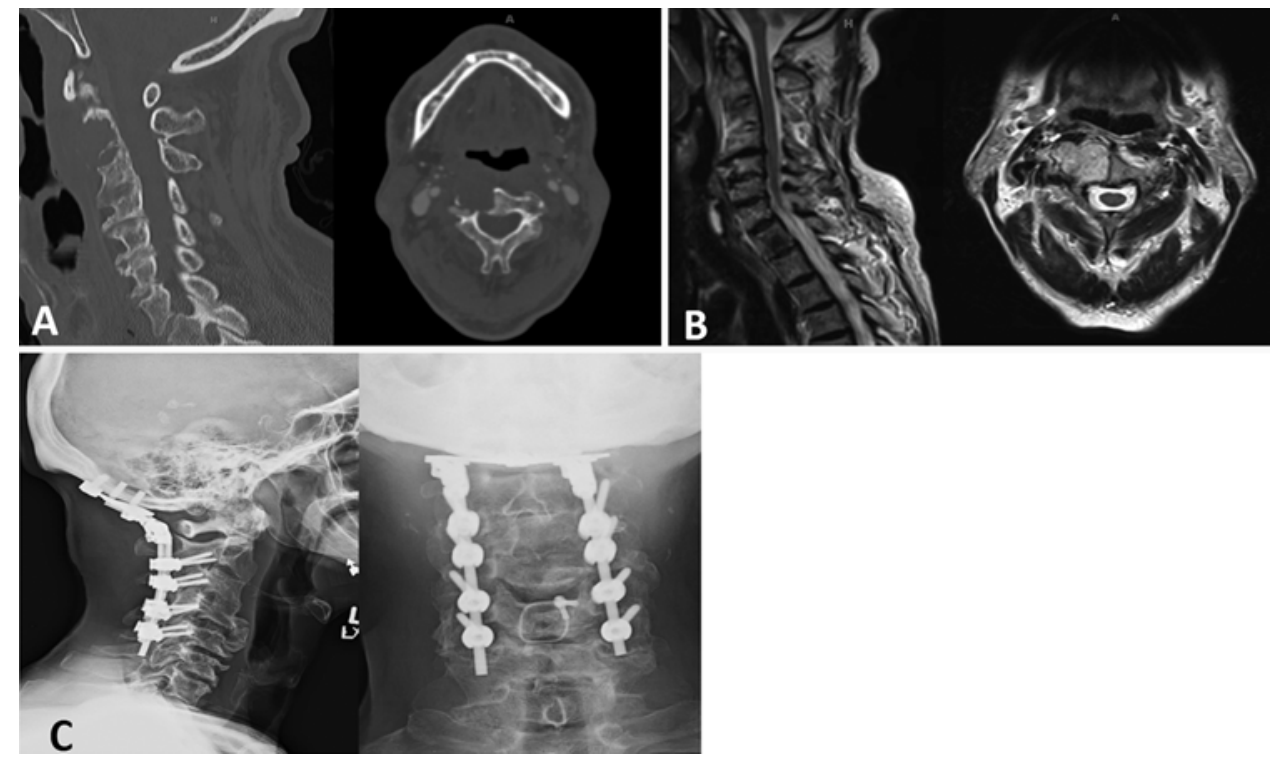

FIG. 1. Case 1. Images obtained in a 71-year-old male with metastatic lung cancer to C-2. Preoperative CT scans (A) of the cervical spine demonstrate a large C-2 osteolytic lesion. T2-weighted MR images (B) show an increase in signal intensity at the right side of C-2 body with minimal posterior structure involvement. Postoperative radiographs (C) demonstrate posterior occipitocervical stabilization using an occipital plate and lateral mass screws.

therapy in 12 patients (80\%). Eight patients (53.33\%) used a hard collar postoperatively, and the average wear time was 2.25 months (range 1-3 months).

Mean follow-up was 11.2 months (range 0-87 months). In the follow-up period, no local recurrences were diagnosed in any patient after fixation and radiation, and no revision occipitocervical surgeries were required. Thirteen patients (76\%) died of disease progression. Median survival time was 10.3 months (range 0-195 months) after surgery. Although all patients had a predicted survival $>6$ months according to Tomita scoring, 6 patients died of disease progression within 6 months after treatment (excluding the 1 early death from myocardial infarction). Bone fusion was assessed in 9 patients (60\%) postoperatively (6 on flexion/extension radiographs and 3 on CT scans). Fusion was determined as less than $1 \mathrm{~mm}$ of motion at the fused level (more than $4 \mathrm{~mm}$ of motion at an adjacent level was used to determined adequate flexion/extension) or as bony union demonstrated on CT. The average latest postoperative fusion assessment period was $562.56 \pm$ 779.81 days (range 191-2603 days). Results showed that all 9 patients had solid fusion. Five patients lived more than 2 years after surgery; however, fusion was noted in only 4 of the patients ( 3 on flexion/extension radiographs and 1 on CT scan), but all 4 patients showed good fusion.

\section{Discussion}

Craniocervical/occipitocervical junction metastatic tumors have been reported to account for just $0.5 \%$ of spinal metastases. ${ }^{2}$ Given the rare incidence of suboccipital metastases, previous publications reporting the efficacy of operative treatment have been limited by small series sizes ${ }^{1,10,16,21,24}$ and variations in disease. ${ }^{3,26}$ Importantly, numerous types of instrumentation have been used in these studies, including occipital pins,,$^{19}$ transarticular screw fixation with a hook plate technique, ${ }^{20}$ Ransford loops, ${ }^{7}$ and
Luque rods..$^{3,8,13}$ Few patients underwent instrumentation with an occipital plate and lateral mass screws., ${ }^{4,810,12}$

In the literature, most patients with CCJ metastases present with neck or occipital pain. ${ }^{1-3,6,8,9,13,18,19,24-26,28} \mathrm{Be}$ cause of the relatively large volume of space available for the spinal cord in the upper cervical spine, neurological deficits from tumors at this location are actually quite rare. ${ }^{1,3,8,18,28}$ Mean age at presentation is typically between

TABLE 1. Summary of clinical results among 15 patients with metastasis at the axis vertebra

\begin{tabular}{|c|c|}
\hline Variable & Results \\
\hline \multicolumn{2}{|l|}{$\operatorname{Sex}(\%)$} \\
\hline Male & $10(66.67)$ \\
\hline Female & $5(33.33)$ \\
\hline Average age in yrs (range) & $64.8 \pm 11.8(48-80)$ \\
\hline Average $\mathrm{CCl}$ (range) & $9.73 \pm 1.57(7-12)$ \\
\hline \multicolumn{2}{|l|}{ Primary site (\%) } \\
\hline Breast & $4(26.67)$ \\
\hline Lung & $4(26.67)$ \\
\hline Bladder & $2(13.33)$ \\
\hline Myeloma & $2(13.33)$ \\
\hline Melanoma & $2(13.33)$ \\
\hline Renal cell carcinoma & $1(6.67)$ \\
\hline Average op time in mins (range) & $215.2 \pm 57.2(120-324)$ \\
\hline Average blood loss in ml (range) & $259.9 \pm 272.4(50-1100)$ \\
\hline Average preop VAS score & $5.50 \pm 2.99$ \\
\hline Average postop VAS score & $1.90 \pm 2.56$ \\
\hline Average hospital LOS in days (range) & $7.2 \pm 3.7(3-16)$ \\
\hline Average FU in mos (range) & $11.2(0-87)$ \\
\hline
\end{tabular}

$\mathrm{CCl}=$ Charlson Comorbidity Index; FU = follow-up; LOS = length of stay. Values represent the number (\%) of patients unless otherwise indicated. Averages are presented \pm SD. 


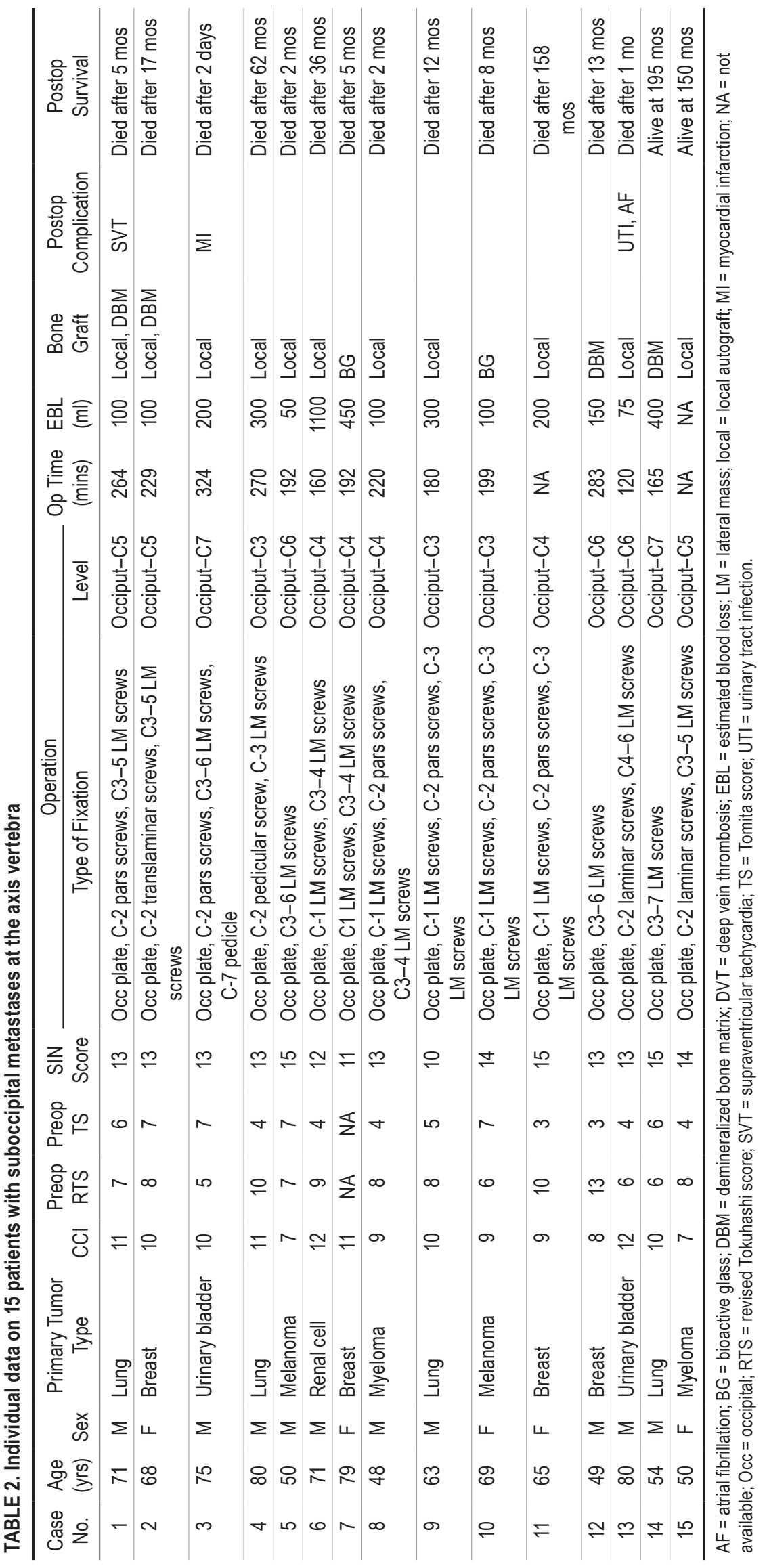


50 and 70 years, ${ }^{26}$ and the most common tumor types are breast, lung, renal, and prostate cancers. ${ }^{1-3,6,8,9,13,18,19,28}$ These findings all mirror those in our patient series.

Radiotherapy alone can effectively treat some patients with occipitocervical metastases who have normal spinal alignment or minimal fracture-subluxations. ${ }^{17}$ Bilsky et al. described 33 patients with symptomatic metastatic tumors involving the atlantoaxial spine. ${ }^{2}$ Twenty-five of the patients underwent nonoperative treatment including external beam radiation therapy (23/25 patients) and chemotherapy (2/25 patients). Most of the patients (23/25) had significant pain resolution until death or at the last followup assessment. However, 5 patients required subsequent operations because of significant fracture-subluxations. Significant pain resolution was achieved in all of the surgically treated patients. Despite observing temporary pain relief, Nakamura et al. reported complications of conservative treatment including sudden death from a respiratory arrest after a fall. ${ }^{18}$ Vertebroplasty for C-2 vertebral metastases has been reported to reduce pain and increase stability in palliative treatment..$^{15,20}$

Operative treatment should be considered in patients with $\geq 3.5 \mathrm{~mm}$ subluxation, $>11^{\circ}$ segmental angulation, or fracture-subluxations $>5 \mathrm{~mm} .{ }^{17}$ Additionally, patients with persistent pain and an inability to wean from a cervical collar following nonoperative therapy should also be considered for surgery. ${ }^{7}$ While several studies have reported the use of anterior ${ }^{21}$ or combined anteroposterior approaches $^{3,9,24,26}$ for resection of upper cervical metastases, patients undergoing these approaches often experience complications and significant postoperative morbidity. Most patients undergoing anterior surgery via the extrapharyngeal approach for resection of upper cervical metastases report substantial postoperative dysphagia. ${ }^{12}$ The risk of postoperative morbidity following transoral approaches to the upper cervical spine has been reported as $32 \% .^{11}$

Posterior stabilization for occipitocervical metastases has been reported to provide pain relief and neurological preservation or recovery without the need for anterior decompression. $^{2}$ In a systematic literature review, Fehlings et al. recommended posterior approaches for most craniovertebral junction metastases. ${ }^{4}$ Occipitocervical fixation using screw-rod constructs is effective for irreducible subluxations, providing effective postoperative pain relief and allowing patients to perform activities of daily living. ${ }^{8,13,17,18}$ The few case studies of posterior occipitocervical tumor stabilizations have reported no neurological complications..$^{8,14,17,18}$ Kirchner et al. described 6 upper cervical spine metastases cases that underwent occipitocervical fusion; during the follow-up period, 1 screw in an osteolytic lateral mass was noted to be loose, and 1 construct failed after a fall. ${ }^{14}$ Surgical complications of posterior stabilizations have been noted in several publications and have included atlantoaxial screw dislocation, ${ }^{24}$ wound infection, ${ }^{28}$ bacteremia and meningitis, ${ }^{6}$ deep vein thrombosis, and pneumonia. ${ }^{28}$

To our knowledge, this is one of the largest posterioronly studies to date on occipitocervical metastases managed with posterior-only operative stabilization. Our patients achieved good, predictable pain relief and were able to return to activities of daily living. No intraoperative or postoperative surgical complications were noted.
Additionally, no reoperations due to implant failure were needed. Several postoperative medical complications did occur, including 1 death.

Limitations of this study include its retrospective nature, multiple surgeons, and single-center population. The occipital plate and lateral mass screw fixation was the only type of fixation performed in all patients, and no instrumentation failure occurred. So, we could not compare the effect of other types of fixation in this region. Moreover, all of our patients presented with an intact neurological status, so we could not evaluate the benefits of posterioronly surgery for neurological decompression and recovery. A multicenter study may reveal additional information on how best to treat neurological deficits from occipitocervical tumors and whether different tumor types behave differently in this anatomical location.

\section{Conclusions}

In summary, posterior occipitocervical fixation and fusion without anterior surgery to treat suboccipital metastases cases is not only safe, but also results in good clinical outcomes, particularly with respect to palliating neck pain and improving quality of life.

\section{References}

1. Atanasiu JP, Badatcheff F, Pidhorz L: Metastatic lesions of the cervical spine. A retrospective analysis of 20 cases. Spine (Phila Pa 1976) 18:1279-1284, 1993

2. Bilsky MH, Shannon FJ, Sheppard S, Prabhu V, Boland PJ: Diagnosis and management of a metastatic tumor in the atlantoaxial spine. Spine (Phila Pa 1976) 27:1062-1069, 2002

3. Colak A, Kutlay M, Kibici K, Demircan MN, Akin ON: Two-staged operation on C2 neoplastic lesions: anterior excision and posterior stabilization. Neurosurg Rev 27:189-193, 2004

4. Fehlings MG, David KS, Vialle L, Vialle E, Setzer M, Vrionis FD: Decision making in the surgical treatment of cervical spine metastases. Spine (Phila Pa 1976) 34 (22 Suppl):S108-S117, 2009

5. Fourney DR, Frangou EM, Ryken TC, Dipaola CP, Shaffrey CI, Berven SH, et al: Spinal instability neoplastic score: an analysis of reliability and validity from the spine oncology study group. J Clin Oncol 29:3072-3077, 2011

6. Fourney DR, York JE, Cohen ZR, Suki D, Rhines LD, Gokaslan ZL: Management of atlantoaxial metastases with posterior occipitocervical stabilization. J Neurosurg 98 (2 Suppl):165-170, 2003

7. Frankel HL, Hancock DO, Hyslop G, Melzak J, Michaelis LS, Ungar GH, et al: The value of postural reduction in the initial management of closed injuries of the spine with paraplegia and tetraplegia. I. Paraplegia 7:179-192, 1969

8. Fung KY, Law SW: Management of malignant atlanto-axial tumours. J Orthop Surg (Hong Kong) 13:232-239, 2005

9. George B, Archilli M, Cornelius JF: Bone tumors at the cranio-cervical junction. Surgical management and results from a series of 41 cases. Acta Neurochir (Wien) 148:741-749, 2006

10. Hertlein H, Mittlmeier T, Schürmann M, Lob G: Posterior stabilization of $\mathrm{C} 2$ metastases by combination of atlantoaxial screw fixation and hook plate. Eur Spine J 3:52-55, 1994

11. Jones DC, Hayter JP, Vaughan ED, Findlay GF: Oropharyngeal morbidity following transoral approaches to the upper cervical spine. Int J Oral Maxillofac Surg 27:295-298, 1998 
12. Jónsson B, Jónsson H Jr, Karlström G, Sjöström L: Surgery of cervical spine metastases: a retrospective study. Eur Spine J 3:76-83, 1994

13. Kato Y, Itoh T, Kubota M: Clinical evaluation of Luque's segmental spinal instrumentation for upper cervical metastases. J Orthop Sci 8:148-154, 2003

14. Kirchner R, Himpe B, Schweder B, Jürgens C, Gille JJ, Faschingbauer M: [The clinical outcome after occipitocervical fusion due to metastases of the upper cervical spine: a consecutive case series and a systematic review of the literature.] Z Orthop Unfall 152:358-365, 2014 (Ger)

15. Krüger A, Schnabel M, Hegele A, Ruchholtz S, Stiletto $\mathrm{R}$ : [Transoral vertebroplasty: an alternative for operative treatment of metastases of the upper cervical spine.] Unfallchirurg 112:426-432, 2009 (Ger)

16. Laohacharoensombat W, Suphachatwong C: Occipital pin for rigid occipitocervical fixation in upper cervical metastasis. Bull Hosp Jt Dis Orthop Inst 50:20-26, 1990

17. Moulding HD, Bilsky MH: Metastases to the craniovertebral junction. Neurosurgery 66 (3 Suppl):113-118, 2010

18. Nakamura M, Toyama Y, Suzuki N, Fujimura Y: Metastases to the upper cervical spine. J Spinal Disord 9:195-201, 1996

19. Papp Z, Marosfói M, Szikora I, Banczerowski P: Treatment of C-2 metastatic tumors with intraoperative transoral or transpedicular vertebroplasty and occipitocervical posterior fixation. J Neurosurg Spine 21:886-891, 2014

20. Rhiew R, Manjila S, Dezure A, Tabbosha M, Guthikonda M, Eltahawy H: Minimally invasive anterior vertebroplasty for C-2 metastatic lesions. Neurosurg Focus 25(2):E4, 2008

21. Sjöström L, Olerud S, Karlström G, Hamberg M, Jonsson H: Anterior stabilization of pathologic dens fractures. Acta Orthop Scand 61:391-393, 1990

22. Tokuhashi Y, Matsuzaki H, Oda H, Oshima M, Ryu J: A revised scoring system for preoperative evaluation of metastatic spine tumor prognosis. Spine (Phila Pa 1976) 30:2186-2191, 2005

23. Tomita K, Kawahara N, Kobayashi T, Yoshida A, Murakami H, Akamaru T: Surgical strategy for spinal metastases. Spine (Phila Pa 1976) 26:298-306, 2001

24. Vieweg U, Meyer B, Schramm J: Tumour surgery of the upper cervical spine - a retrospective study of 13 cases. Acta Neurochir (Wien) 143:217-225, 2001

25. Xu R, Sciubba DM, Gokaslan ZL, Bydon A: Metastasis to the occipitocervical junction: a case report and review of the literature. Surg Neurol Int 1:16, 2010
26. Yang X, Wu Z, Xiao J, Teng H, Feng D, Huang W, et al: Sequentially staged resection and 2-column reconstruction for $\mathrm{C} 2$ tumors through a combined anterior retropharyngeal-posterior approach: surgical technique and results in 11 patients. Neurosurgery 69 (2 Suppl Operative):ons184-ons194, 2011

27. Yoshihara H, Yoneoka D: Trends in the surgical treatment for spinal metastasis and the in-hospital patient outcomes in the United States from 2000 to 2009. Spine J 14:1844-1849, 2014

28. Zimmermann M, Wolff R, Raabe A, Stolke D, Seifert V: Palliative occipito-cervical stabilization in patients with malignant tumors of the occipito-cervical junction and the upper cervical spine. Acta Neurochir (Wien) 144:783-790, 2002

\section{Disclosures}

Dr. Buchowski is a consultant for Advance Medical, CoreLink Inc., DePuy Synthes, Gerson Lehrman Group, Globus Medical Inc., K2M Inc., Medtronic Inc., and Stryker Inc.; has teaching arrangements with Broadwater/Vertical Health, DePuy Synthes, Globus Medical Inc., Orthofix, and Stryker; receives royalties from Globus Medical, K2M, and Wolters Kluwer Health; and has a nonfinancial relationship with AOA, CSRS, and AO Foundation. Dr. Wright is a consultant for and receives royalties from NuVasive Inc.

\section{Author Contributions}

Conception and design: Buchowski, Luksanapruksa. Acquisition of data: all authors. Analysis and interpretation of data: Luksanapruksa, Peters. Drafting the article: Luksanapruksa, Peters, Bumpass. Critically revising the article: all authors. Reviewed submitted version of manuscript: Buchowski, Wright, Valone, Peters, Bumpass. Approved the final version of the manuscript on behalf of all authors: Buchowski. Statistical analysis: Luksanapruksa, Bumpass. Administrative/technical/material support: Peters. Study supervision: Wright.

\section{Correspondence}

Jacob M. Buchowski, Department of Orthopaedic Surgery, Washington University in St. Louis, BJC Institute of Health, 425 S Euclid Ave., Campus Box 8233, St. Louis, MO 63110. email: buchowskij@wustl.edu. 